\title{
Is Raised Intraocular Pressure a Bad Prognostic Sign in Acute Corneal Graft Rejection?
}

\author{
G. G. W. ADAMS, K. E. STEVENSON, C. M. KIRKNESS, A. D. McG.STEELE, \\ N. S. C. RICE
}

London

\begin{abstract}
Summary
One hundred and forty acute corneal rejection episodes in 94 patients were studied retrospectively. Sixteen episodes in 15 eyes were associated with raised intraocular pressure (IOP) on admission, three of whom had had previously elevated IOP. At six weeks, six $(37.5 \%)$ stil required hypotensive therapy. Five eyes with raised IOP at rejection had lost vision at six weeks. Five of the six eyes with graft failure at review had raised IOP either pre-graft, at rejection or at follow-up. Eyes grafted for herpes simplex keratitis with hypertensive rejection episodes had a higher mean admission IOP, with a more short-lived rise than other eyes.
\end{abstract}

Glaucoma is a common cause of visual loss after penetrating keratoplasty in both phakic and aphakic patients. ${ }^{1-11}$ The reported incidence of glaucoma in aphakic eyes after keratoplasty ranges from $25 \%$ to $70 \%$ and glaucoma may be more likely to persist or worsen if there was evidence of raised pressure pre-operatively. ${ }^{10-12}$ The overall incidence may be as high as $30 \% .^{2}$ Sustained increases in intraocular pressure (IOP) are known to affect the corneal endothelium adversely. Decreased endothelial cell function and increased endothelial cell loss have been reported in the presence of elevated IOP in both experimental animal models and in human subjects with acute angle closure glaucoma. ${ }^{13,14}$ A study of animal models with and without penetrating keratoplasty suggests that the endothelium of graft tissue is more susceptible to damage by raised IOP than normal, non-grafted, corneal endothelium. ${ }^{13}$

Despite the wealth of literature on the incidence and risk factors of post keratoplasty glaucoma (PKPG) we are aware of only one publication on the association of an acute rise in IOP with corneal graft rejection. ${ }^{7}$ This retrospective study was instituted to examine the relationship between corneal graft rejection and glaucoma and to ascertain whether elevated IOP at the time of acute corneal allograft rejection is associated with poor graft survival or with a prolonged increase in IOP

\section{Patients and Methods}

The standard management of patients with acute corneal graft rejection attending the corneal clinic at Moorfields Eye Hospital is immediate admission to the hospital for intensive topical steroid therapy (gutt Dexamethasone $0.1 \%$ or gutt Prednisolone forte $1 \%$ half hourly by day and hourly by night in conjunction with subconjunctival injection of steroids, usually Betamethasone $4 \mathrm{mg}$ as necessary, usually on admission and the subsequent day). The dosage of all steroids is titrated against the clinical response. Patients

From: Corneal Clinic, Moorfields Eye Hospital, London.

Correspondence to: Miss G. G. W. Adams, Professorial Unit, Moorfields Eye Hospital, City Road, London EC1V 2PD. 


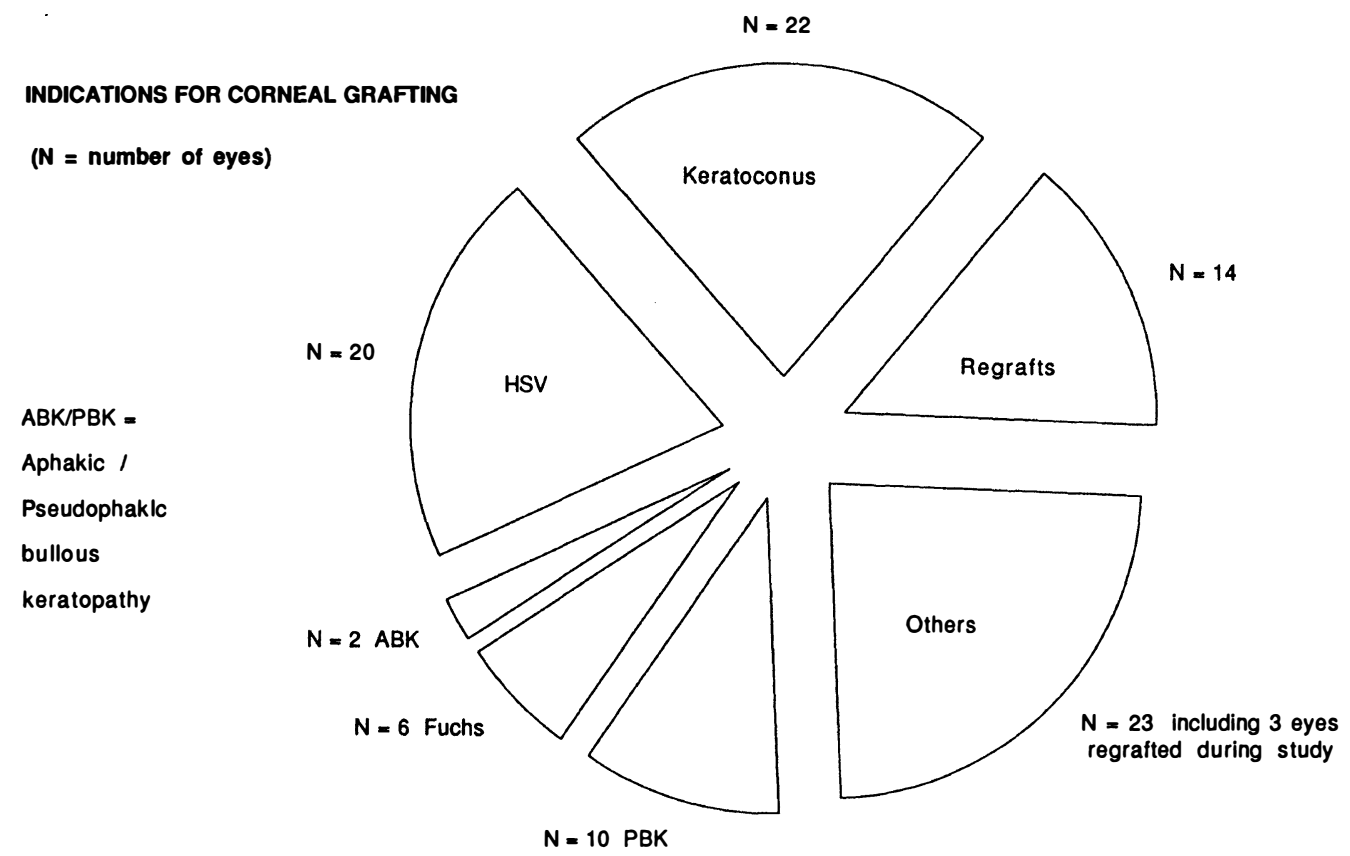

Fig. 1. Indications for corneal grafting.

admitted to Moorfields Eye Hospital between March 1985 and April 1988 with a diagnosis of acute corneal graft rejection were identified from hospital activity analysis data.

The criteria for diagnosis of graft rejection included a Khodadoust line, keratic precpitates, flare and cells, Krachmer's spots, and unexplained graft oedema. From the records of these patients we obtained data on the indication for corneal grafting and the presence of pre-operative glaucoma. The IOP, best corrected visual acuity and the ocular therapy on admission were recorded. Similar data were recorded at six weeks after rejection and the corneal graft status was also noted. If the IOP was elevated on admission, the duration of the rise and its treatment were recorded.

\section{Results}

One hundrend and forty rejection episodes in 94 patients (46 male and 48 female) with an age range of 21 to 96 years were identified. The indications for corneal grafting are presented in Figure 1, from which it can be seen that the two commonest conditions requiring keratoplasty were keratoconus and herpes simplex keratitis, with 22 eyes grafted for keratoconus and 20 grafted for HSV. These two groups had an almost identical number of rejection episodes with 31 for keratoconus and 30 for herpes simplex keratitis. It is interesting to compare this with the commonest reasons for keratoplasty which in this institution between 1985-1987 were keratoconus $(34.2 \%)$ and regrafts $(17.2 \%)$ with viral keratitis accounting for $3.2 \%$ of grafts. ${ }^{15}$ This is illustrated in Figure 2. Forty-one eyes (58 rejection episodes) had been grafted for a variety of disorders including interstitial keratitis, trauma, corneal dystrophies and buphthalmos. Because of their particular problems regrafts were included as a separate group (14 eyes and 21 rejection episodes). Three eyes were regrafted during the course of the study and were included in both other and regraft diagnostic groups. Thirty-nine rejection episodes $(27.8 \%)$ occurred in those with a previously documented elevated IOP. None of these rejection episodes were in tissue matched grafted material. Very few keratoplasties in this institution involve tissue matched grafts, and in the previous survey less than $1 \%$ involved tissue typed material. (Bates, personal communication). 
INDICATIONS FOR CORNEAL GRAFTING

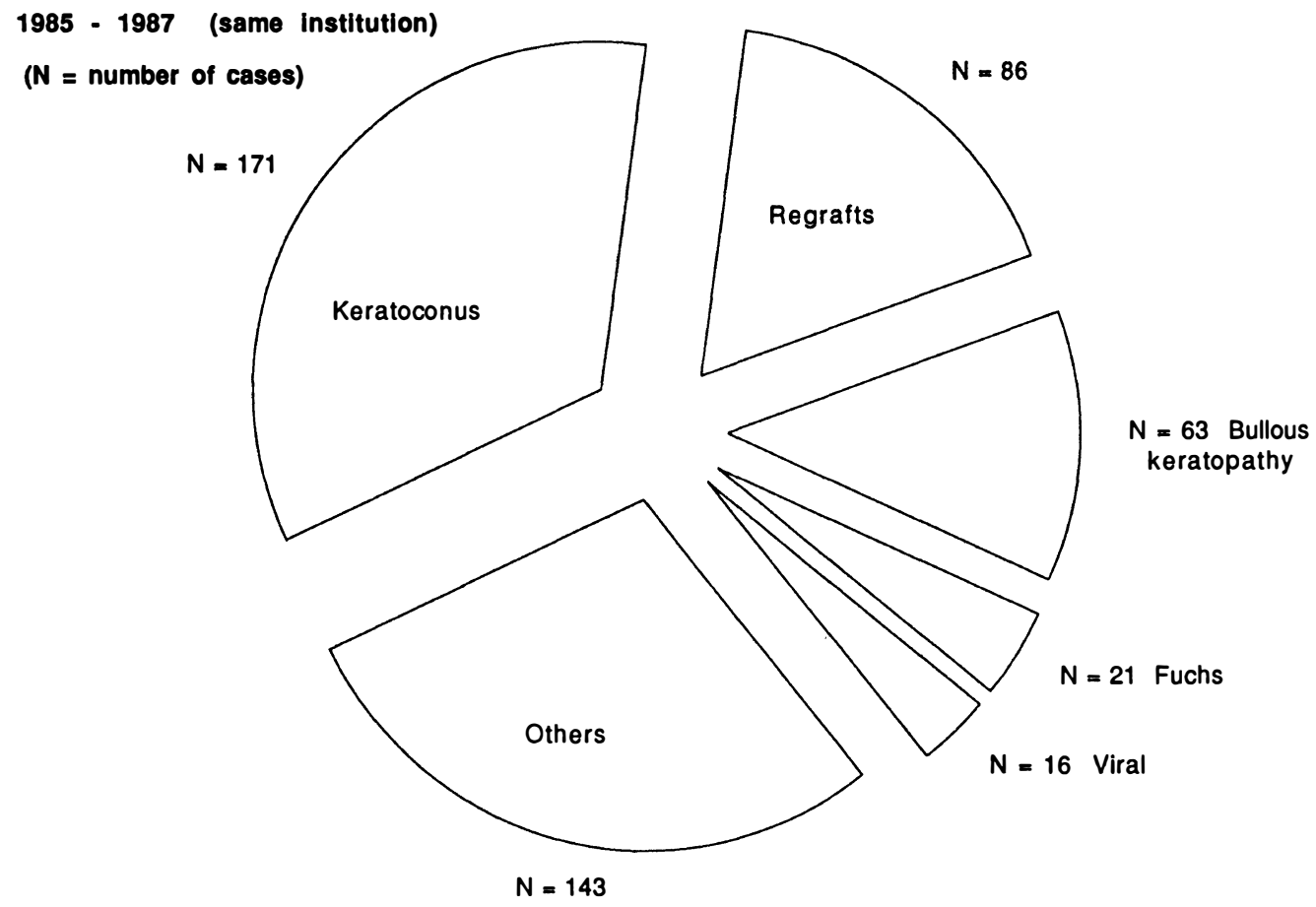

Fig. 2. Indications for corneal grafting 1985-1987(same institution).

Increased intraocular pressure at presentation Sixteen episodes $(11.4 \%)$ of corneal graft rejection were associated with an acute rise in IOP to $22 \mathrm{mmHg}$ or higher. Of these sixteen episodes four were in regrafts, three in grafts for herpes simplex keratitis, two in keratoconus grafts, two in grafts for Fuch's dystrophy, and the rest came from the others category and included one episode for an infective graft, another for idiopathic bullous keratopathy, one grafted, elsewhere, for unknown reasons. There were two hypertensive rejection episodes in one patient who had been grafted for bullous keratopathy after previous drainage surgery for chronic simple glaucoma. Six of these were still requiring hypotensive therapy at six weeks follow-up, when four were on topical therapy alone and two on a combination of topical and systemic therapy (Fig. 3). The patient with two rejection episodes and previous glaucoma used topical treatment at follow-up after both episodes.

Three episodes associated with elevated IOP at the time of admission occurred in aphakic grafts. Of the four hypertensive rejection episodes in regrafts, one was also aphakic. The three hypertensive rejection episodes that occurred in grafts for herpes simplex keratitis had a higher admission IOP with a mean of $40 \mathrm{mmHg}$ compared to the others $(26.7 \mathrm{mmHg})$, but this difference is not significant (Student's $t$-test). Of these 16 episodes at the time of rejection, four had not been on topical steroids, eight had been on steroid drops four times per day or less, and only four had been on more frequent treatment to prevent graft rejection.

\section{Increased intraocular pressure during treatment}

More patients required hypotensive medication at six weeks than on admission. Usually this treatment was commenced during their out-patient follow-up. Twenty-seven episodes of graft rejection (19.3\%) required hypotensive therapy at six weeks, 20 on topical hypotensives and seven requiring combination systemic and topical therapy for IOP control 


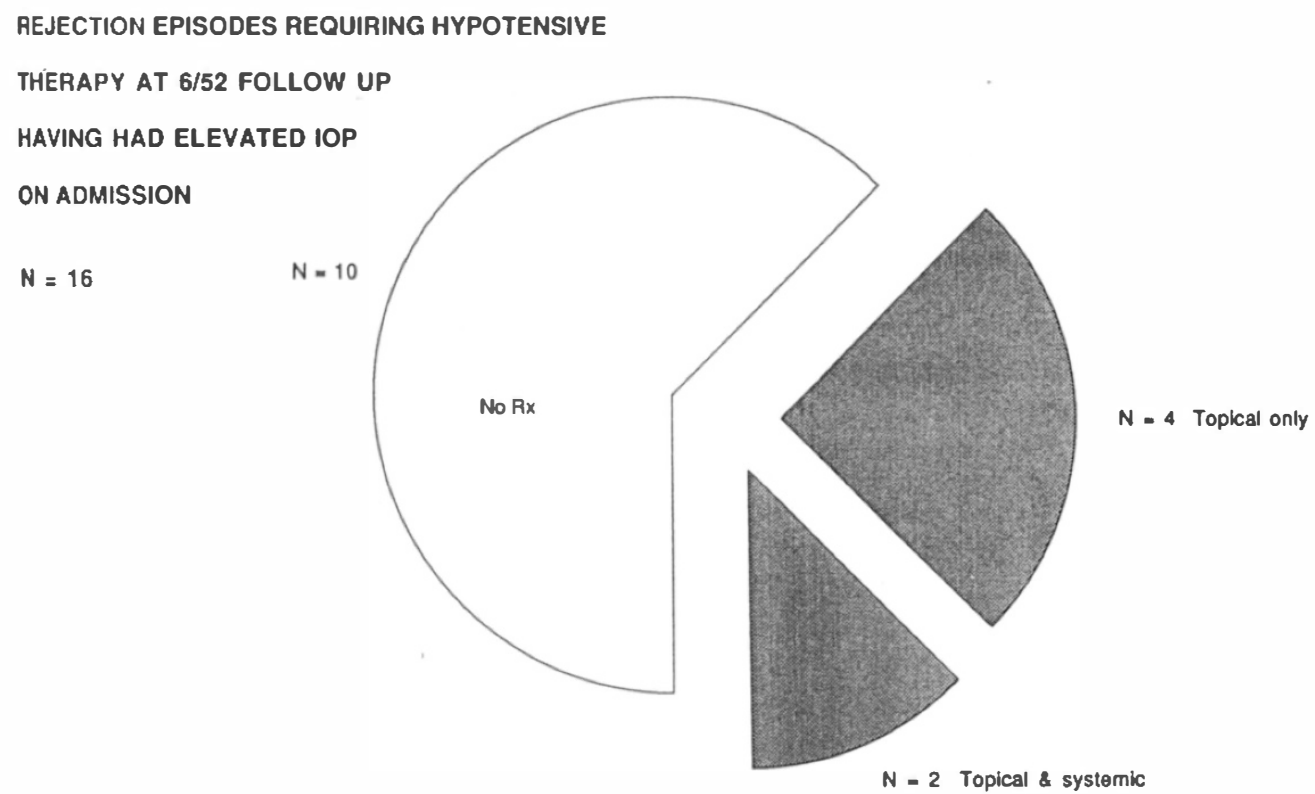

Fig. 3. Rejection episodes requiring hypotensive therapy at 6/52 follow'-up having had elevated IOP on admission.

(Fig. 4). Of these 27 episodes with high IOP at six weeks, $13(48 \%)$ were in patients with documented elevation of IOP prior to rejection. Patients with a history of elevated IOP were more likely to require additional antiglaucoma treatment as a result of a rejection episode, $\mathrm{p}<0.05$. Of the 30 rejection episodes in patients grafted for herpes simplex kera-

\section{HYPOTENSIVE RX AT 6 WEEK FOLLOW UP}

$$
N=20 \text { Topical Rx only }
$$

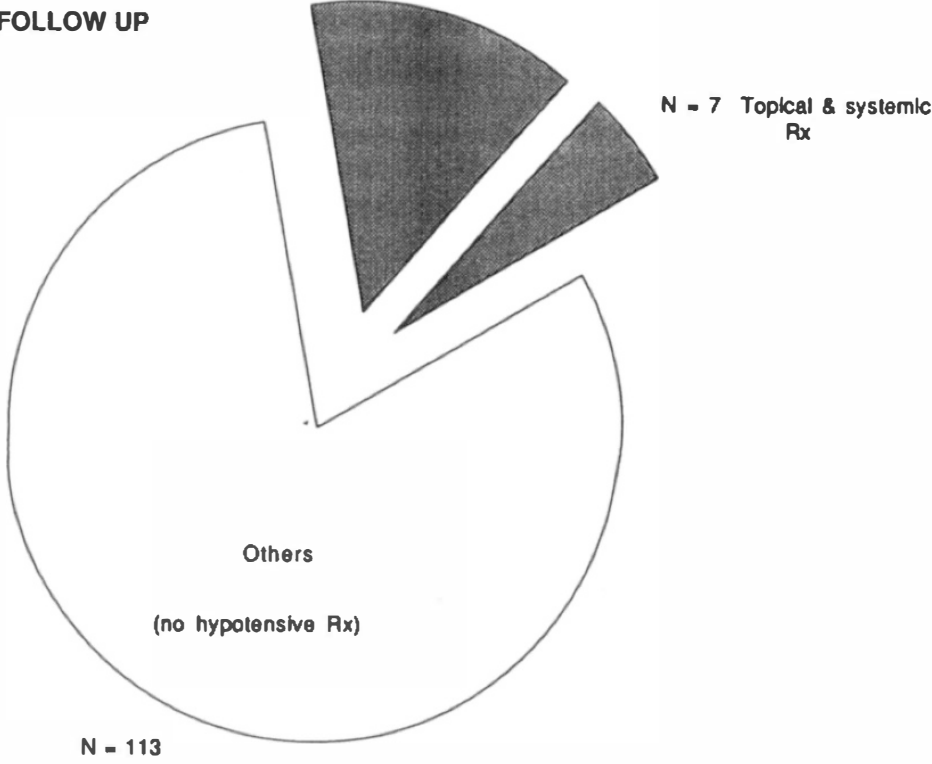

Fig.4. Hypotensive treatment at 6-keek follon-up. 


\section{EPISODES WERE} FOLLOWED BY A RECORDED DECREASE IN BEST CORRECTED VA OF 1 LINE OR GREATER AT $6 / 52$

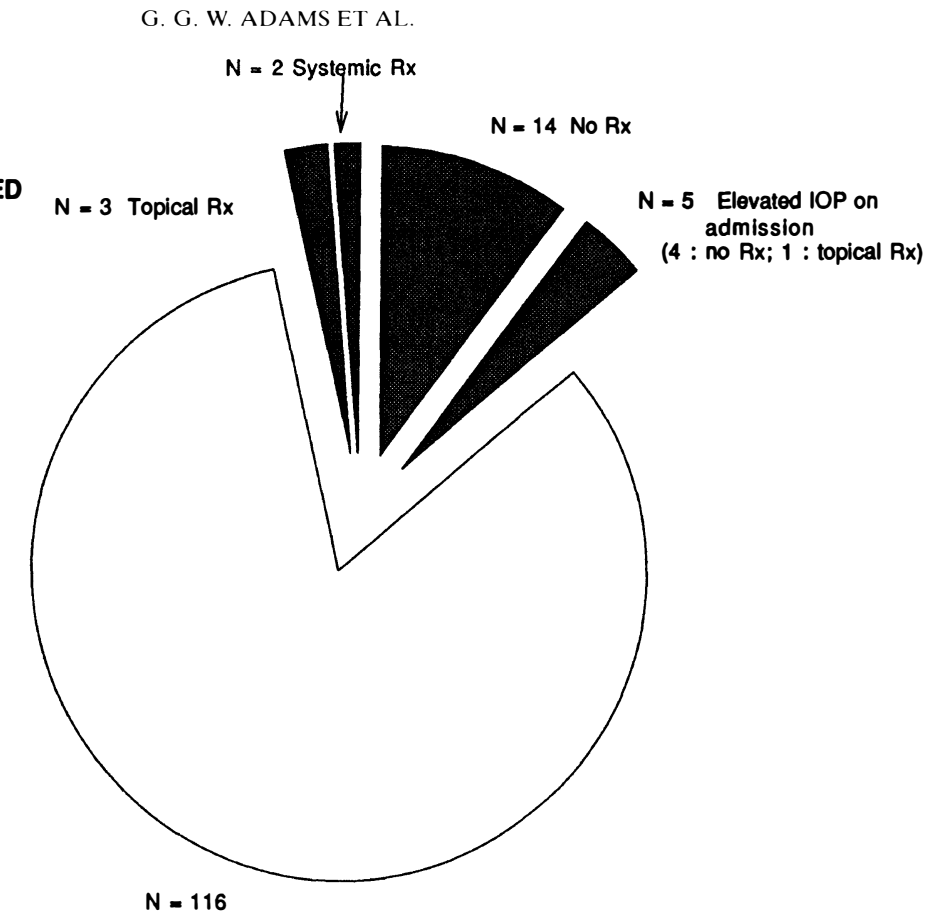

Fig. 5. 24 episodes were followed by a recorded decrease in best corrected VA of one line or greater at 6/52.

titis, only one required hypotensive therapy at the six-week follow-up. This was a patient with previously elevated IOP. No patient had required surgical treatment for control of elevated pressure by the six-week follow-up period.

\section{Visual acuity}

Twenty-four episodes of graft rejection (17\% of the total rejection episodes) were followed by a recorded decrease in best corrected visual acuity of one line or greater on the Snellen chart at the six-week follow-up. Nineteen of these 24 episodes had normal IOP at the time of graft rejection, (15.3\% of the 124 episodes without raised pressure at rejection). The other five episodes had raised IOP at the time of rejection $(31.2 \%$ of the group with hypertensive rejection episodes). This is illustrated in Figure 5.

Of the 19 normotensive rejection episodes, five who had not required hypotensive treatment on admission were using hypotensive treatment (three on topical therapy alone and two requiring systemic therapy) at review. Of the five hypertensive rejections only one required treatment, topically, at follow-up.
Only one of these hypertensive episodes was associated with loss of more than two Snellen lines when vision went from 1/60 to perception of light due to a retinal detachment.

\section{Graft survival}

Six grafts failed as a result of rejection although only four lost vision since the other two had poor but unchanged vision (CF). Two grafts failed in patients with hypertensive graft rejection episodes. One of these patients who had a pressure on admission of $38 \mathrm{mmHg}$, progressed to phthisis bulbi with an underlying retinal detachment, (see above). The other patient whose graft failed had been regrafted for aphakic bullous keratopathy. He had no previous history of glaucoma, had an admission IOP of $23 \mathrm{mmHg}$, and did not require hypotensive therapy at six weeks. Of the four normotensive rejection episodes to be followed by total graft failure, three had a history of raised pressure, and two were on anti-hypertensive treatment at follow-up.

\section{Discussion}

We can only find one paper in the English lan- 
guage literature postulating a link between graft rejection and glaucoma. ${ }^{16}$ Four cases of corneal allograft rejection were described associated with elevated intraocular pressure. It was suggested that increased IOP at the time of rejection was likely to be related to increased prostaglandins, inflammatory cells, pigment and fibrin in the anterior chamber. This would be expected to settle as the rejection episode was controlled. Prolonged elevation of the IOP could be a consequence of the steroids used for the control of the rejection episode. Because of the damage that can be done to an endothelium already compromised by the rejection mechanism the need for monitoring IOP in graft rejection was stressed.

\section{IOP on admission}

Our study has shown that corneal graft rejection was associated with an elevation in IOP at the time of admission in $11.4 \%$ of cases. Of these 16 episodes seven required antiglaucoma medication at the six-week follow-up. Three episodes occurred in two patients with previously evelated IOP, one of whom had had previous drainage surgery for chronic simple glaucoma. It has been suggested that mild to moderate increases in IOP (between 30 and $40 \mathrm{mmHg}$ ) associated with rejection episodes and possibly steroid induced will settle and that the antiglaucoma therapy can be stopped as the steroid therapy is reduced. Significant increases in IOP of $40 \mathrm{mmHg}$ or greater may be associated with a previous history of anterior segment inflammation where the outflow channels are obstructed by pigment and debris. These cases may require long-term antiglaucoma therapy. ${ }^{16}$ We cannot confirm this impression. In our study the highest IOP in association with rejection episodes $>40 \mathrm{mmHg}$ were in patients grafted for herpes simplex keratitis or infection. Of 30 rejection episodes in patients grafted for herpes simplex corneal scarring (a potent cause of anterior segment inflammation) only one patient required hypotensive therapy at six weeks. This patient had a history of glaucoma prior to keratoplasty.

\section{IOP during treatment}

This study also demonstrates that IOP may become raised in the course of treatment of a rejection episode. The six-week review was chosen as all patients were still attending for regular follow-up at this time. Bourne indicates that elevated IOP persisting this long after an incident is likely to be permanent.? This is probably a different mechanism to that associated with the acute rejection episode.

Twenty-seven of 140 (19.3\%) cases of graft rejection required antiglaucoma medication at six weeks. Of these $13(48 \%)$ were in patients with previously documented pregraft elevations in IOP. The cause of the elevated IOP at six weeks may be related to further compromise of the outflow of the eye, damaged at the time of the initial disease process or at the time of grafting, by the inflammatory debris and mediators produced by the rejection episode itself. A steroid response may also be responsible for raised IOP. That more patients with previously documented glaucoma were requiring hypotensive therapy at six weeks supports this hypothesis. A steroid response is known to be more common in patients with primary open angle glaucoma than in non-glaucoma patients.' Corticosteroids are essential to reverse the graft rejection process but the IOP must be closely monitored and any elevation treated, to minimize further damge to corneal endothelium already compromised by the rejection process.

\section{Herpes simplex keratitis}

It is well documented that elevation of IOP may accompany herpes simplex uveitis and this trend to higher admission IOP levels of the herpes group compared with the other diagnostic categories emphasises the difficulty in differentiating early corneal graft rejection from a recurrence of herpes simplex keratouveitis in these patients. ${ }^{17}$ It is also interesting to note that the only one of the 30 rejection episodes in patients $(3.3 \%)$ grafted for herpes simplex requiring hypotensive treatment at six weeks was. in a patient with previously elevated IOP, compared with 26 of 110 episodes $(23.6 \%)$ with other pre-graft diagnoses. This difference is significant $(\mathrm{p}<0.005)$ and suggests that any rise in IOP associated with a herpetic graft rejection episode is short lived. It may be related more to inflammatory debris 
in the angle or a 'trabeculitis' than to a steroid induced glaucoma.

\section{Prognosis}

Raised IOP in association with a rejection may be a bad prognostic sign since of the 16 patients with elevated IOP on admission for corneal graft rejection five were documented to have lost vision by six weeks. This is $31.2 \%$ of the hypertensive group who lost vision at follow-up. Although the figures are small particularly in the hypertensive group it does appear that a rise in IOP at the time of acute corneal allograft rejection leads to an increased risk of a reduction in visual acuity.

The presumption that elevated IOP damages corneal endothelium and that this may shorten the life of the graft is suggested by analysis of the six rejection episodes that were followed by graft failure. All of these patients were aphakic or pseudophakic. Five of the six total graft failures were in patients with elevated IOP occurring either pre-graft, at the time of graft rejection or at six weeks follow-up suggesting that IOP does influence graft survival. It would appear that in the short term, elevation of IOP during the graft rejection episode may be associated with a reduction in visual acuity, and that a history of pressure elevation in association with a corneal graft does increase the likelihood of graft failure. Aphakic or pseudophakic patients comprised five of the six graft failures emphasising the high risk of graft failure in this group of patients.

\section{Conclusions}

This study has clearly demonstrated an association between a sudden rise in IOP and graft rejection episodes. It suggests that a sudden rise in IOP in an eye with a penetrating keratoplasty might indicate a developing rejection episode and care should be taken in the supervision of such a patient. This sign should not be overlooked.

In our study corneal allograft rejection was accompanied by an increase in IOP in $11.4 \%$ of cases. We feel therefore that a sudden unexplained rise in intraocular pressure should be considered as part of the spectrum of signs of acute corneal graft rejection. Of those cases with elevated IOP on admission
$43.75 \%$ still required therapy at six weeks. Patients grafted for herpes simplex keratitis appeared to have a marked but short lived rise in IOP which may reflect the difficulty in distinguishing between graft rejection and a recurrence of herpes simplex kerato-uveitis.

In the short follow-up of this study $31.2 \%$ of the group with elevated pressure at the time of rejection lost acuity. Five of six total graft failures were in patients with elevated IOP, either pre-graft, on admission, or at six weeks suggesting that IOP control is important for longterm survival of the graft.

From our findings raised intraocular pressure in the presence of a corneal graft is a poor prognostic factor for graft survival, and hypertension at the time of graft rejection is followed by a higher chance of reduced acuity in the short term. We would emphasise the need for meticulous monitoring and control of intraocular pressure in patients with corneal grafts, especially those with aphakia or regrafts.

Key words: corneal graft rejection, intraocular pressure, glaucoma.

\section{References}

'Insler MS, Cooper HD, Kastl PR, Caldwell DR: Penetrating keratoplasty with trabeculectomy. Am J Ophthalmal 1985, 100: 593-5.

${ }^{2}$ Kirkness CM and Moshegov C: Post-keratoplasty glaucoma. Eye 1988, 2 (Suppl): S19-26.

${ }^{3}$ Zimmerman TJ: Elevated intraocular pressure after aphakic keratoplasty: Iatrogenic disease and prevention. Ann Ophthalmol 1978, 931-2.

${ }^{+}$Foulks GN: Glaucoma associated with penetrating keratoplasty. Ophthalmology 1982, 94: 871-4.

${ }^{5}$ Foulks GN, Perry HD, Dohlman CH: Oversize corneal donor grafts in penetrating keratoplasty. Ophthamology 1979, 86: 490-4.

${ }^{6}$ Olson RJ: Aphakic keratoplasty. Determining donor tissue size to avoid elevated intraocular pressure. Arch Ophthalmol 1978, 96: 2274-6.

${ }^{7}$ Bourne WM, Davison JA, O'Fallon WM: The effect of oversize donor buttons on postoperative intraocular pressure and corneal curvature phakic penetrating keratoplasty. Ophthalmology 1982, 89: $242-6$.

${ }^{8}$ Irvine AR and Kaufman HE: Intraocular pressure following penetrating keratoplasty. Am J Ophthalmol 1969, 68: 835-44.

${ }^{9}$ Goldberg DB, Schanzlin DJ, Brown SI: Incidence of increased intraocular pressure after keratoplasty. Am J Ophthalmol 1981, 92: 372-7.

${ }^{10}$ Karesh JW and Nirankari VS: Factors associated with glaucoma after penetrating keratoplasty. $\mathrm{Am}$ J Ophthalmol 1983, 96: 160-4.

${ }^{11}$ McDonnell PJ, Robin JB, Schanzlin DJ, Minckler D, Baerveldt G, Smith RE, Heuer D: Molteno 
implant for control of glaucoma in eyes after penetrating keratoplasty. Ophthalmology 1988, 95: 242-6.

${ }^{12}$ Olson RJ and Kaufman HE: Prognostic factors after aphakic keratoplasty. Am J Ophthalmol 1978, 86: 510-5.

${ }^{13}$ Charlin R and Polack FM: The effect of elevated intraocular pressure on the endothelium of corneal grafts. Cornea 1982, 1: 241-9.
${ }^{1+}$ Olson T: The endothelial cell damage in acute glaucoma, on the thickness response to intraocular pressure. Acta Ophthalmol 1980, 58: 257-66.

${ }^{15}$ Morris RJ and Bates AK: Changing indications for keratoplasty. Eye 1989, 3: 455-9.

${ }^{16}$ Polack FM: Graft rejection and glaucoma. Am J Ophthalmol 1986, 101: 294-7.

${ }^{17}$ Easty DL: Virus diseases of the eye. London: LloydLuke (Medical Books) Ltd, 1985: 152. 